BI-OBJECTIVE ANALYSIS OF WASTE LOAD ALLOCATION USING FUZZY LINEAR PROGRAMMING

W.E. Hathhorn and

Y.K. Tung

1989

Journal Article

WWRC $-89-34$

In

Water Resources Management

Volume 3

Wade E. Hathhorn

Department of Civil Engineering

University of Texas

Austin, Texas

Yeou-Koung Tung

Wyoming Water Research Center

Department of Statistics

University of Wyoming

Laramie, Wyoming 


\title{
Bi-Objective Analysis of Waste Load Allocation Using Fuzzy Linear Programming
}

\author{
WADE E. HATHHORN \\ Department of Civil Engineering. University of Texas, Austin, TX 78712, U.S.A. \\ and \\ YEOU-KOUNG TUNG \\ Wyoming Water Research Center and Statistics Department, University of Wyoming, Laramie, \\ WY 82071 , U.S.A.
}

(Received: 6 September 1988; revised: 11 April 1989)

\begin{abstract}
Because of its complexity from both a legal and economic standpoint, the problem of optimal waste load allocation is multiobjective by nature and should be treated accordingly. To perform this task, an optimization technique known as fuzzy linear programming is utilized in solving a multipledischarge, two-objective waste load allocation problem. The two objectives considered are: (1) the maximization of waste discharge and (2) the minimization of the largest difference in equity measure between the various dischargers. Results from this study reveal that fuzzy linear programming is a valuable tool for solving the multiple-objective water quality management problems. Moreover, it is shown that the selection of a linear or logistic membership function in providing preference criteria between the two objects, has no effect on the 'best compromising solution'.
\end{abstract}

Key words. Waste load allocation, water quality management, multiple-objective analysis, fuzzy linear programming.

\section{Introduction}

Ever since the introduction of the original Streeter-Phelps equation in 1925 (Streeter and Phelps, 1925), researchers have conducted a number of studies in attempts to understand more fully the natural assimilative capacity of streams and the interaction of waste discharge and dissolved oxygen (DO) within the stream environment. Moreover, with the conception and growth in popularity of a number of optimization techniques, the problem of optimal waste load allocation (WLA) has been formulated and solved using a variety of mathematical techniques. The idea of optimizing waste discharge to a receiving stream is certainly not new to the field of water quality management. The work presented by Loucks et al. (1967) and ReVelle et al. (1968) are some of the notable contributions to the use of singleobjective linear programming (LP) in solving the problem of deterministic optimal WLA. Other optimization techniques, such as dynamic and geometric programming, have also been utilized by Liebman and Lynn (1966) and Ecker (1975).

Although these techniques have been praised by many as useful tools in the 
regulation and management of aquatic environments, some have criticised their over-simplification within the decision-making process in arriving at the so-called 'optimum solution'. It should be pointed out that much of the research work conducted in this area, to date, has centered around the use of a single-objective function optimization (i.e. the minimization of treatment costs or the maximization of waste discharge). The so-called 'optimum solutions' are obtained based on a single measure of utility for the feasible alternatives. The validity or usefulness of optimal solutions obtained in this fashion may be questioned. In reality, most environmental problems are inherently complex from both a legal and economic viewpoint. It is unlikely that a truly optimum solution can be obtained by using only one measure of utility to identify the best alternative, Rather, a solution based on a number of desired objectives which consider a multitude of legal and economic factors would likely provide a more realistic solution to the WLA problem.

To perform such an analysis, the methods of multi-objective analysis can be utilized. It is within this framework that the analyst is simultaneously allowed to incorporate the tradeoff of a variety of noncommensurable, mutually conflicting objectives. A number of multi-objective analysis techniques have already been developed. For a thorough review of multi-objective methodologies, readers are referred to Monarchi et al. (1973) and Cohon (1978). It is not the intention of this article to develop another, but rather to utilize an existing methodology believed to be a potentially useful tool in solving such problems. Of particular interest in this study are the methodologies for solving the tradeoff of a bi-objective model. The methodology used here is known as fuzzy linear programming (FLP) and will be shown to be a tractable technique for solving the WLA problem within a biobjective framework.

\section{General Framework of the Multi-Objective Optimization Model}

\subsection{VECTOR OPTIMIZATION}

Within the multi-objective framework, the problem consists of more than one scaler objective function. The problem is one of 'vector optimization' which can be expressed as

$$
\operatorname{Max} \mathrm{Z}(\mathrm{X})=\left[Z_{1}(\mathrm{X}), Z_{2}(\mathrm{X}), \ldots, Z_{k}(\mathrm{X})\right]
$$

subject to

$$
\mathrm{g}(\mathrm{X}) \leqslant 0
$$

where $\mathrm{z}(\mathrm{X})$ is a $k$-dimensional vector of the objective functions, $\mathrm{X}$ is an $n$-dimensional vector containing the decision variables, and $\mathrm{g}(\mathrm{X})$ is an $m$-dimensional vector of constraints. 


\subsection{THE OBJECTIVE FUNCTIONS}

Two objective functions are considered for the WLA problem in this study: (1) the maximization of waste discharge and (2) the minimization of the largest differences in equity measures between the various waste dischargers. Each of these objectives are discussed in greater detail in the following paragraphs.

The first objective, i.e. the maximization of waste discharge, can be expressed as

$$
\operatorname{Max} Z_{1}=\sum_{j=1}^{N}\left(B_{j}+D_{j}\right),
$$

where $B_{j}$ and $D_{j}$ are the decision variables representing effluent waste discharge (mg/l BOD) and DO deficit (mg/l) at each discharge location $j$, respectively; $N$ is the total number of discharge locations. The decision variables, effluent waste discharge and DO deficit, were selected in accordance with the Streeter-Phelps equation. It should be pointed out that the concentrations of instream DO are not only a function of the waste input, but also the DO deficit in the waste effluent. The incorporation of a waste transfer function, through the use of the StreeterPhelps equation, into the model formulation is discussed in the model constraints section of this paper.

By contrast, the most common objective function used is that of minimizing treatment costs. Here, the first objective is to maximize waste discharge and effluent DO deficit. Although not apparent at first, there is an analogy between the two. Maximizing waste discharge and effluent $D O$ deficits may be translated to minimizing waste treatment and, thus, reduced costs.

The second objective considers the equity between the various waste dischargers. It is unreasonable to consider the WLA model complete without incorporating the idea of 'fairness' into the model formulation. There have been several articles citing the importance of equity considerations in the WLA problem (Gross, 1965; Loucks et al., 1967; Miller and Gill, 1976; Brill et al., 1976).

Recognizing the importance of equity consideration in the WLA process, the choice must then be made as to the type of equity measure to be used. Based on the conclusion drawn by Chadderton et al. (1981), two types of equity are considered in this study: (1) equal percent removal and (2) equal effluent concentration. Because the values of equity measure could vary among dischargers, a single measure representing the worst case is adopted. Hence, the second objective is to minimize the largest difference in equity between the various waste dischargers.

$$
\operatorname{Min} Z_{2}=\delta E_{\max }
$$

where $\delta E_{\max }$ is a decision variable representing the largest difference in equity between the various dischargers; i.e., $\delta E_{\max }=\max \left\{\left|E_{i}-E_{j}\right|\right\}$ for all $i \neq j$ in which $E_{i}$ is the equity measure for the $i$ th waste discharger. The types of equity utilized in this study and their importance are discussed later. 


\subsection{MODEL CONSTRAINTS}

The constraints in a mathematical programming model define the physical, biological, legal, and economic limitations of the system. In this study, the objectives of the WLLA problems are to maximize waste discharge and to minimize the largest difference in equity. However, this action is not without its own limitations. Obviously, the unrestricted waste discharge to a stream environment will pose detrimental effects to the aquatic biota, eventually producing an anaerobic environment in which all forms of desired aquatic life cease to exist. Hence, the inclusion of constraints which properly defined and protect the use of the limited resources within the stream environment are essential in the WLA problem formulation.

\section{Constraints on Water Quality}

The most common requirement of the WLA problem has been the assurance of minimum concentrations of $D O$ throughout the river system in an attempt to support the desired aquatic biota. Specifically, the constraint which relates the response of DO to the addition of in-stream waste, is generally defined by the StreeterPhelps equation or its variations (ReVelle et al., 1968; Bathala et al., 1979). By utilizing the Streeter-Phelps equation, each control point and discharge location becomes a constraint in a mathematical programming model providing a check on water quality at that location. Within a generalized framework, water quality constraints are derived by applying the Streeter-Phelps equation in succession across each reach within the stream environment under investigation. A typical water quality constraint for the model proposed could be expressed as follows:

$$
\sum_{j=1}^{n_{i}} \Theta_{i j} B_{j}+\sum_{j=1}^{n_{i}} \Omega_{i j} D_{j} \leqslant R_{i}, \quad i=1,2, \ldots, M,
$$

where $\Theta_{i j}$ and $\Omega_{i j}$ are the technological transfer coefficients indicating the relative impact on DO concentration at downstream locations, $i$, resulting from a waste input at an upstream location, $j ; n_{i}$ is the number of the dischargers upstream of the control point $i ; R_{i}$ represents the allowable $\mathrm{DO}$ available for the utilization of waste discharge at the control point $i$; and $M$ is the total number of control points.

\section{Constraints on Treatment Equity}

In addition to the constraints satisfying water quality, constraints are also employed to define equity between the various dischargers along the stream system. Without the inclusion of equity considerations in the WLA model, any attempts to maximize waste discharge could result in the allocation of large quantities of waste to the upstream users, while the downstream dischargers would be required to treat their 
effluents at levels of maximum possible efficiency. (This is especially true for fastmoving streams.) In mathematical form, constraints for equity can be generally expressed as

$$
\left|E_{j}-E_{j}\right| \leqslant \delta E_{\max }, \text { for } j \neq j^{\prime},
$$

where $E_{j}$ represents the equity measure considered for discharger $j, \delta E_{\max }$ (a decision variable) represents the largest difference in equity between the two dischargers $j$ and $j$. In order to incorporate these constraints into an LP model, they must be expressed as linear functions of the decision variables (i.e., effluent waste concentration at each discharge location, $B_{j}$ ). In following this approach, the constraints for equity when considering equal percent removal between the dischargers can be written as

$$
\left|\frac{B_{j}}{I_{j}}-\frac{B_{j^{\prime}}}{I_{j^{\prime}}}\right| \leqslant \delta E_{\max }, \text { for } j \neq j^{\prime},
$$

and when considering equal effluent concentrations

$$
\left|B_{j}-B_{j^{\prime}}\right| \leqslant \delta E_{\max }, \text { for } j \neq j^{\prime},
$$

where $I_{j}$ is the influent raw waste concentration (mg/l BOD) at discharge locations $j$.

Additionally, it should be noted that for any given stream system, one or more of the discharges considered may be an influent tributary. The discharge from a tributary should be excluded from the consideration of equity in order to prevent undue restrictions being placed on the required treatment levels assigned to other dischargers. Therefore, provisions should be included to account for tributary flows and their waste inputs in order to identify the entirety of potential waste sources.

\section{Constraints on Treatment Efficiency}

The final set of constraints to consider are those defining the acceptable range of the treatment efficiency. To illustrate its use, a range between 35 and $90 \%$ removal of raw waste at each discharge location was arbitrarily selected for this constraint. The treatment efficiency constraints for each discharge location then can be expressed as

$$
0.35 \leqslant 1-\frac{B_{j}}{I_{j}} \leqslant 0.90, \text { for all } j=1,2, \ldots, N \text {. }
$$

Certainly, the reader may argue that the limits set on treatment efficiency are antiquated. Nonetheless, these limits were selected solely as a means to illustrate the use of the methods presented here. By changing these limits, only the size of the feasible region if affected, not the utility of the methods themselves. It is the intent of the paper to focus the presentation on the use of a methodology for which the problem of WLA may be analyzed within a bi-objective framework. 


\section{Fuzzy Linear Programming in Multi-Objective Analysis}

The foundation for this methodology was born out of the fuzzy set theory introduced by Zadeh (1965). Zadeh's original studies were in search of improved decision analysis in the ares of expert systems and artificial intelligence. Since its conception, the application of fuzzy set theory to the field of mathematical programming has been led by a number of early research works, including those written by Zimmerman $(1976,1984)$ and Kickert (1978). More recently, the popularity of its use has grown to include some notable works by Sakawa et al. (1987), Orlovsky (1984), Korhonen et al. (1987), Sakawa (1983) and Bogardi et al. (1983).

In order to completely grasp the use of these procedures, the methodologies associated with ELP can be divided into two central concepts: (1) defining the membership functions and (2) outlining the FLP model formulation. Each of these'. concepts are discussed in detail below.

\subsection{THE MEMBERSHIP FUNCTION}

The most important point to note in implementing the FLP formulation is that the objective function and system constraints are defined by a unique membership function. This membership function acts as a surrogate characterization of preference in determining the desired outcome for each of the objectives within the multiobjective framework. The process to appropriately define the membership function is performed in such a manner as to allow the function to take on values in the interval $[0,1]$. The membership function, denoted $\mu_{k}$ for the $k$ th objective, should at least satisfy the following conditions:

$$
\mu_{k}= \begin{cases}0, & \text { if } Z_{k}(X) \leqslant L_{k}, \\ 0<\mu_{k}<1, & \text { if } L_{k}<Z_{k}(X)<U_{k}, \\ 1 & \text { if } Z_{k}(X) \geqslant U_{k},\end{cases}
$$

where $Z_{k}(\mathrm{X})$ is the outcome of $k$ th objective; $L_{k}$ and $U_{k}$ represent the least acceptable and most desirable outcome for $Z_{k}(\mathrm{X})$, respectively.

By defining the membership function in such a manner, the analyst and decisionmaker, working interactively, can program a level of desirability for the various outcomes of each of the objectives into the model formulation. Once completed, the membership function acts as a scaling device in assigning a level of acceptance to each of the alternatives considered in the multi-objective formulation. Ultimately, the best-compromise solution can be identified as the alternative which attains the highest level of desirability while simultaneously satisfying the model constraints.

Several membership functions have been employed in FLP: (1) linear, (2) exponential, (3) hyperbolic, and (4) logistic (Sakawa and Yano, 1985). This list is by no means intended to represent the entirety of membership functions in existence. Although a variety of such functions are accessible, the linear and logistic membership 
functions are selected as the means of defining the level of desirability in this study. Through an appropriate transformation, the logistic membership function can be linearized preserving the linearity of the LP formulation.

The linear form of the membership function (shown in Figure 1), can be expressed as

$$
\mu_{k}\left(Z_{k}\right)=\left\{\begin{array}{cl}
0, & \text { if } Z_{k}(X) \leqslant L_{k}, \\
\frac{1}{d_{k}}\left[Z_{k}(X)-L_{k}\right], & \text { if } L_{k}<Z_{k}(X)<U_{k}, \\
1 & \text { if } Z_{k}(X) \geqslant U_{k},
\end{array}\right.
$$

where $d_{k}$ is the range of outcomes for $Z_{k}(\mathrm{X})$ determined by $\left(U_{k}-L_{k}\right)$.

The logistic membership function (shown in Figure 2), is defined as

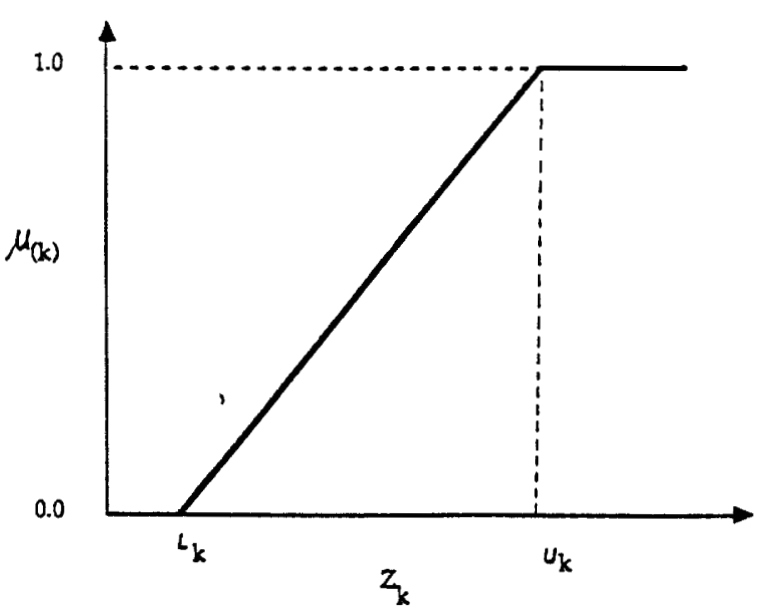

Fig. 1. Linear membership function.

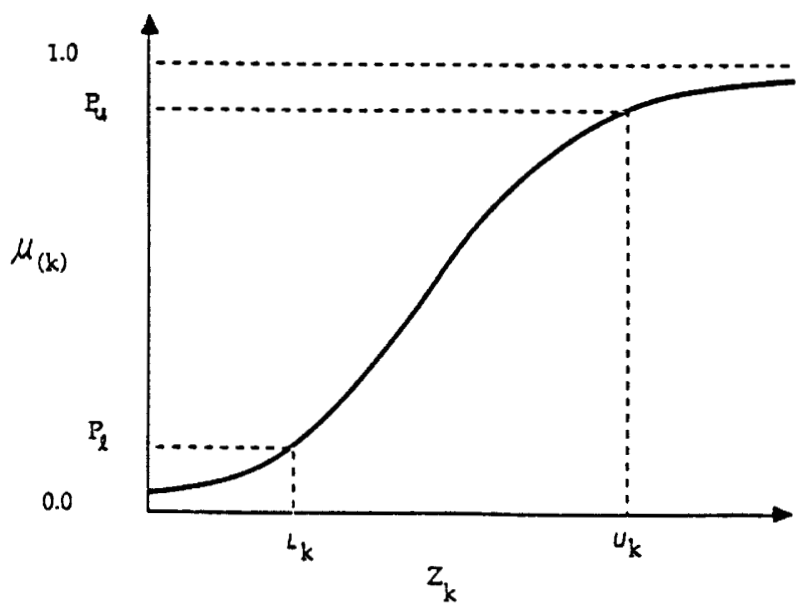

Fig. 2. Logistic membership function. 


$$
\mu_{k}\left(Z_{k}\right)= \begin{cases}P_{l}, & \text { if } Z_{k}(\mathrm{X}) \leqslant L_{k}, \\ \frac{1}{1+\exp \left[-\alpha_{k}-\beta_{k} Z_{k}(\mathrm{X})\right]}, & \text { if } L_{k}<Z_{k}(\mathrm{X})<U_{k}, \\ P_{u}, & \text { if } Z_{k}(\mathrm{X}) \geqslant U_{k},\end{cases}
$$

where $P_{l}$ and $P_{u}$ represent the degree of decision-maker's preference corresponding to the lowest and highest attainable values for the $k$ th objective, where $\alpha_{k}$ and $\beta_{k}$ are constants in the membership function which can be determined by

$$
\begin{aligned}
& \alpha_{k}=\left(\frac{U_{k}}{d_{k}}\right) \cdot \ln \left(\frac{P_{l}}{1-P_{l}}\right)-\left(\frac{L_{k}}{d_{k}}\right) \cdot \ln \left(\frac{P_{u}}{1-P_{u}}\right), \\
& \beta_{k}=\left(\frac{1}{d_{k}}\right)\left[\ln \left(\frac{P_{u}}{1-P_{u}}\right)-\ln \left(\frac{P_{l}}{1-P_{l}}\right)\right] .
\end{aligned}
$$

In general, values for $P_{u}$ and $P_{l}$ are selected between 0.95 and 0.99 and 0.10 and 0.05 , respectively.

\subsection{THE GENERALIZED FLP MODEL FORMULATION}

Given the theory behind the FLP model formulation,the goal of this technique is to obtain a best-compromise solution which maximizes the level of desirability for each of the objectives in the multi-objective problem. More precisely, the goal is to maximize the minimum attainable membership function value for each of the objectives. That is, the model adopts a 'max-min' principle. This is accomplished by introducing a new decision variable, $\lambda$, representing the minimum attainable membership function value of all the objectives. The problem is then formulated in a generalized LP format as follows:

\section{$\operatorname{Max} \lambda$}

subject to

$$
\begin{aligned}
& \mathbf{g}(\mathrm{X}) \leqslant 0, \\
& \mu_{k}\left[Z_{k}(\mathrm{X})\right]-\lambda \leqslant 0, \text { for all } k=1,2, \ldots, K,
\end{aligned}
$$

where $K$ is the number of objectives considered in the problem formulation.

In solving the FLP model formulation, the procedures can be outlined in four basic steps:

(1) Solve the multiple-objective problem using only one objective at a time, ignoring all others. Repeat the process until all objectives have been evaluated.

(2) From the solutions in step (1), determine the best $\left(U_{k}\right)$ and worst $\left(L_{k}\right)$ outcomes for each of the objectives, $k$.

(3) Define the membership function for each objective, $\mu_{k}\left[Z_{k}(X)\right]$, from the results 
obtained for the objective in step (2).

(4) Redefine the objective function to maximize the minimum $\left\{\mu_{k}\left[Z_{k}(X)\right]\right\}$, include constraints Equation (16) (in addition to those controlling water quality, treatment, and equity), and solve the final formulation.

When performed correctly, these four steps provide an effective means of obtaining a direct solution to the best-compromise alternative in the multi-objective model formulation (Zimmerman, 1976, 1984; Ignizio, 1982).

\section{Bi-Objective WLA Using Fuzzy Linear Programming}

\subsection{THE LINEAR MEMBERSHIP MODEL}

The bi-objective WLA problem considered herein has two objectives: (1) the maximization of total waste discharge and (2) the minimization of the maximum difference in equity. Referring to the generalized LP format presented earlier, the FLP formulation can be expressed as

$\operatorname{Max} \lambda$

subject to

(1) Original constraints in WLA model:

$$
\begin{aligned}
& \sum_{j=1}^{n_{i}} \Theta_{i j} B_{j}+\sum_{j=1}^{n_{i}} \Omega_{i j} D_{j} \leqslant R_{i}, \quad \mathrm{i}=1,2, \ldots, M, \\
& \left|E_{j}-E_{j^{\prime}}\right| \leqslant \delta E_{\max }, \quad \text { for } j \neq j^{\prime}, \\
& 0.35 \leqslant 1-\frac{B_{j}}{I_{j}} \leqslant 0.90, \text { for all } j=1,2, \ldots, N .
\end{aligned}
$$

(2) Linear membership constraints:

(i) for the maximization of total waste discharge

$$
\frac{1}{d_{1}} \sum_{j=1}^{N}\left(B_{j}+D_{j}\right)+\lambda \leqslant \frac{L_{1}}{d_{1}},
$$

(ii) for the minimization of maximum equity difference

$$
\frac{1}{d_{2}} \delta E_{\max }+\lambda \leqslant \frac{L_{2}}{d_{2}}
$$


where

$$
\lambda=\min \left[\frac{1}{d_{2}}\left(L_{2}-\delta E_{\max }\right), \frac{1}{d_{1}}\left(\sum_{j=1}^{N}\left(B_{j}+D_{j}\right)-L_{1}\right)\right] .
$$

\subsection{THE LOGISTIC MEMBERSHIP MODEL}

Referring to Equation (19) we realize that a transformation of variables must be made in order to develop a linearized function for $Z_{k}(\mathrm{X})$ before the logistic function can be incorporated into a linear programming framework. Similar to the linear membership case, the constraints associated with the objectives in the FLP formulation can be expressed as

$$
\mu\left(Z_{k}\right)=1 /\left\{1+\exp \left[-\alpha_{k}-\beta_{k} Z_{k}(\mathrm{X})\right]\right\} \geqslant \lambda .
$$

After some algebraic manipulations, Equation (20) can be written as

$$
\alpha_{k}+\beta_{k} \cdot Z_{k}(X) \geqslant \ln \left(\frac{\lambda}{1-\lambda}\right)
$$

Although $\lambda$ is the decision variable to be maximized, the term $\ln [\lambda /(1-\lambda]$ poses no difficulty, since it is a strictly montonically increasing function of $\lambda$. To maximize $\lambda$ will also maximize $\ln [\lambda /(1-\lambda)]$. With this property, we can define a new decision variable $\epsilon=\ln [\lambda /(1-\lambda)]$. Thus, Equation (21) can be reduced to linear form as

$$
-\beta_{k} \cdot Z_{k}(\mathrm{X})+\epsilon \leqslant \alpha_{k} .
$$

Notice that the value for $\epsilon$ can be negative, zero, and positive (i.e., $\epsilon$ is unrestrictedin-sign). When using the simplex algorithm for solving an LP model, a nonnegativity requirement for decision variables is normally imposed. To satisfy this requirement, the decision variable $\epsilon$ (which is unrestricted-in-sign) can be replaced by the difference of two nonnegative decision variables defined as $\epsilon=\epsilon^{+}-\epsilon^{-}$.

Using the two new nonnegative decision variables $\epsilon^{+}$and $\epsilon^{-}$, a relationship utilizing the logistic membership can be incorporated into a multi-objective LP format. The resulting FLP model can be expressed as

$$
\operatorname{Max} \epsilon^{+}-\epsilon^{-}
$$

subject to

(1) Original constraints including Equation (5), (6), (9);

(2) Logistic membership constraints:

(i) for the maximization of total waste load

$$
-\beta_{1}\left(\sum_{j=1}^{N} B_{j}+D_{j}\right)+\epsilon^{+}-\epsilon^{-} \leqslant \alpha_{1},
$$




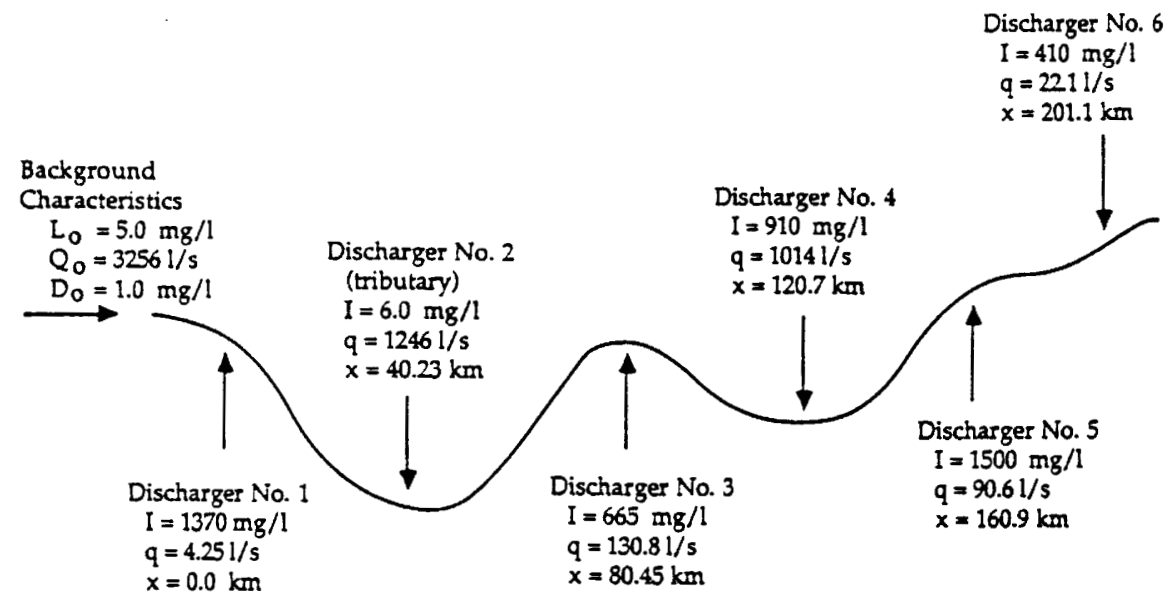

Fig. 3. Schematic sketch of example river system in WLA problem.

(ii) for the minimization of maximum equity difference

$$
-\beta_{2} \cdot \delta E_{\max }+\epsilon^{+}-\epsilon^{-} \leqslant-\alpha_{2},
$$

(iii) nonnegative constraints:

$$
\epsilon^{+} \geqslant 0, \quad \epsilon^{-} \geqslant 0, \quad \delta E_{\max } \geqslant 0, \text { and } B_{j} \geqslant 0, \quad D_{j} \geqslant 0 \text {, for all } j .
$$

The coefficients $\alpha$ 's and $\beta$ 's in Equation (24) and (25) can be computed by Equation (13) and (14), respectively.

Tabie I. Data of physical characteristics used in the example of WLA models

(a) Stream characteristics for each reach

\begin{tabular}{llllll}
\hline Reach & $\begin{array}{l}\text { Deoxygenation } \\
\text { coefficient } \\
(1 / \text { days })\end{array}$ & $\begin{array}{l}\text { Reaeration } \\
\text { coefficient } \\
(1 / \text { days })\end{array}$ & $\begin{array}{l}\text { Average stream } \\
\text { velocity } \\
(\mathrm{km} / \text { day })\end{array}$ & $\begin{array}{l}\text { Raw waste } \\
\text { concen. } \\
(\mathrm{mg} / 1 \mathrm{BOD})\end{array}$ & $\begin{array}{l}\text { Effluent } \\
\text { flow rate } \\
\left(\mathrm{m}^{3} / \mathrm{sec}\right)\end{array}$ \\
\hline 1 & 0.6 & 1.84 & 26.4 & 1370 & 0.0042 \\
2 & 0.6 & 2.13 & 26.4 & 6 & 1.2460 \\
3 & 0.6 & 1.98 & 26.4 & 665 & 0.1308 \\
4 & 0.6 & 1.64 & 26.4 & 910 & 1.0141 \\
5 & 0.6 & 1.64 & 26.4 & 1500 & 0.0906 \\
6 & 0.6 & 1.48 & 26.4 & 410 & 0.0221 \\
\hline
\end{tabular}

(b) Background characteristics

\begin{tabular}{lll}
\hline $\begin{array}{l}\text { Upstream waste concentration } \\
(\mathrm{mg} / \mathrm{l} \mathrm{BOD})\end{array}$ & $\begin{array}{l}\text { Upstream flow rate } \\
\left(\mathrm{m}^{3} / \mathrm{sec}\right)\end{array}$ & $\begin{array}{l}\text { Upstream DO deficit } \\
(\mathrm{mg} / \mathrm{l})\end{array}$ \\
\hline 5.0 & 3.2568 & 1.0 \\
\hline
\end{tabular}




\section{Application of Fuzzy Linear Programming to Example WLA Problem}

A hypothetical stream system involving six discharging points outlined in Figure 3 and Table I has been used for example illustration. The FLP models based on the two different membership functions are solved using the two-objective model and the four basic steps outlined previously. The best and worst objective function values of the two objectives considered are given in Table II.

\section{Results and Discussion}

The FLP solutions to the two-objective WLA problem for the six-reach example using a linear membership function are displayed in Tables III and IV. Specifically, Table III contains the best-compromise solution to the example WLA problem when the equity of equal percent removal between the dischargers is considered, while Table IV is associated with the equity of equal effluent concentrations. When

Table II. The best $\left(U_{k}\right)$ and worst $\left(L_{k}\right)$ solutions for each objective when considering the two types of equity

(a) Equity type: equal percent removal

\begin{tabular}{lcc}
\hline & \multicolumn{2}{l}{ Bounds } \\
\cline { 2 - 3 } Objectives & $L_{k}$ & $U_{k}$ \\
\hline$Z_{1}:$ Maximize total waste discharge $(\mathrm{mg} / \mathrm{l})$ & 2691 & 493 \\
$Z_{2}:$ Minimize maximum difference in equity $(\%)$ & 0.0 & 54.3 \\
\hline
\end{tabular}

(b) Equity type: equal effluent concentration

\begin{tabular}{lcc}
\hline & \multicolumn{3}{l}{ Bounds } \\
\cline { 2 - 3 } Objectives & $L_{k}$ & $U_{k}$ \\
\hline$Z_{1}:$ Maximize total waste discharge $(\mathrm{mg} / \mathrm{l})$ & 2691 & 758 \\
$Z_{2}:$ Minimize maximum difference in equity $(\mathrm{mg} / \mathrm{l})$ & 0.0 & 878 \\
\hline
\end{tabular}

Table III. Optimal allocation of waste for the two-objective problem using FLP with the linear membership function and the equity of equal percent removal

\begin{tabular}{lllllll}
\hline Discharger & No. 1 & No. $2^{\mathrm{a}}$ & No. 3 & No.4 & No.5 & No.6 \\
\hline $\begin{array}{l}\text { Allowable waste } \\
\text { discharge }(\mathrm{mg} / \mathrm{l})\end{array}$ & 539 & 6 & 262 & 142 & 590 & 161 \\
$\begin{array}{l}\text { Required percentage } \\
\text { raw waste removal }(\%)\end{array}$ & 60.7 & 0 & 60.7 & 84.5 & 60.7 & 60.7 \\
\hline
\end{tabular}

a Discharger No. 2 is a tributary. 
Table IV. Optimal allocation of waste for the two-objective problem using FLP with the linear membership function and the equity of equal effluent concentration

\begin{tabular}{lllllll}
\hline Discharger & No.1 & No. 2 & No. 3 & No. 4 & No.5 & No.6 \\
\hline $\begin{array}{l}\text { Allowable waste } \\
\text { discharge (mg/l) }\end{array}$ & 502 & 6 & 4232 & 129 & 502 & 266 \\
$\begin{array}{l}\text { Required percentage } \\
\text { raw waste removal }(\%)\end{array}$ & 63.4 & 0 & 35.0 & 85.8 & 66.5 & 35.0 \\
\hline
\end{tabular}

a Discharger No. 2 is a tributary.

comparing the two sets of optimal allocations, the total allowable waste discharge for the equity of equal percent removal (1700 mg/l BOD) is less than the total for the equity of equal effluent concentrations (1837 mg/l BOD). This is the result of the unique characteristics possessed by each of the membership functions associated with the individual formulations. By considering the two different types of equity, two separate and distinct problems are formulated according to the FLP procedures. Once solved, the individual model formulations result in unique solutions.

Additionally, the solution procedures were repeated using the logistic membership function as reported in Equation (20) to (22). The best-compromise allocations obtained for each type of equity using either a logistic or linear membership function were identical. Because of the unique analytic expressions associated with the two membership functions, it was originally thought that these results were erroneous or coincidental to the example system chosen. Upon further analytical investigation, the identical results obtained or the linear and logistic membership functions were proven to be always true. The formal proof to support this statement is shown by Hathhorn (1986).

In the proof, the arithmetic sum of the linear membership constraints given by Equation (17) and (18) is shown to be identical to the sum of the logistic membership constraints given by Equation (24) and (25). The physical interpretation here is that the feasible domain described by each of the membership functions share an identical boundary containing the optimal solution. The difference between these feasible domains is related to the total volume of feasible domain.

Clarifications of these arguments can be made by referring to the schematic diagram shown in Figure 4 which represents the feasible domain corresponding to the twoobjective FLP problem. The domain bounded by points $A B C D$ and $A B E F$ are assumed to represent the feasible space for the linear and logistic membership functions, respectively. Additionally, point $O$ (which is shared by each of the domains) represents the optimal solution to the two-objective WLA problem in the FLP framework. By changing the assumption of the membership function, the planes $A B C$ and $A B D$ are repositioned to $A B E$ and $A B F$, respectively. More importantly, the position of the ridge boundary defined by line $A B$ remains unaffected. Hence, the solution 


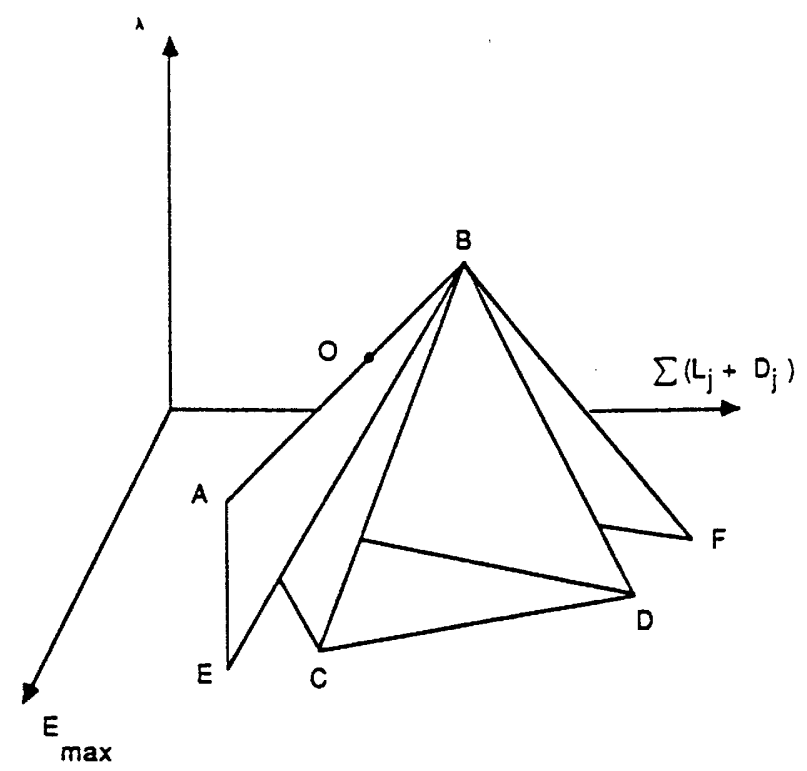

Fig. 4. Feasible region defined by membership functions in WLA model.

of the FLP problem remains unchanged. However, these results should only be considered true for any bi-objective model formulation. Until further analysis is conducted, these conclusions should not be extrapolated to problem formulations considering three or more objectives.

\section{Summary and Conclusions}

In the past, waste load allocation problems have been solved in a single-objective optimization framework. However, most of environmental water quality management problems are multi-objective by nature. In answer to the shortcomings of the single-objective approach, this paper has presented a methodology for solving a waste load allocation problem utilizing the framework of fuzzy linear programming. In essence, fuzzy linear programming applies the min-max principle and prior articulation of preference in attempt to reach the best-compromise solution. It is a rather viable and potentially useful technique for solving multi-objective water quality management problems.

\section{Acknowledgements}

The authors wish to thank the reviewers for their constructive comments on the manuscript. The study was supported by the Wyoming Water Research Center at the University of Wyoming.

\section{References}

Bathala, C. T., Das, K. C., and Jones, W. D., 1979, Assimilative capacity of small streams, J. Environ. Eng. 105(6), 1049-1060. 
Bogardi, I., Bardossy, A., and Duckstein, L., 1983. Regional management of an aquifer for mining under fuzzy environmental objectives, Water Resour. Res. 19(6), 1394-1402.

Brill, E., Liebman, J., and Revelle, C., 1976, Equity measures for exploring water quality management alternatives, Water Resour. Res. 12.

Chadderton, R. A., Miller, A.D., and McDonnell, A. J., 1981, Analysis of waste load allocation procedure, Water Resour. Bull. 17(5), 760-766.

Cohon, J. L., 1978, Multiobjective Programming and Planning, Academic Press, New York.

Ecker, J. G., 1975, A geometric programming model for optimal allocation of stream dissolved oxygen, Management Sci. 21(6), 658-668.

Gross, W. M., 1965, A lawyer looks at stream pollution, Civil Eng. 44-45.

Hathhorn, W. E., 1986, Optimal waste load allocation in a stream environment under uncertainty, MS Thesis, Department of Civil Engineering, University of Wyoming, Laramie, Wyoming.

Ignizio, J. P., 1982, Linear Programming in Single- and Multiple-objective Systems, Prentice-Hall, Englewood Cliffs, NJ.

Kickert, W. J., 1978, Fuzzy Theories on Decision-Making, Martinus Nijhoff, The Hague.

Korhonen, P., Wallenius, J., and Duckstein, L., 1987, Multiple objective linear programming over a fuzzy feasible set, in G. Evans, W. Karwowski, and M. Wilhelm (eds), Fuzzy Methodologies for Industrial and Systems Engineering, Elsevier; Amsterdam.

Liebman, J. C. and Lynn, W. R., 1966, The optimal allocation of stream dissolved oxygen, Water Resour. Res. 2, 581-591.

Loucks, D. P., ReVelle, C. S., and Lynn, W. R., 1967, Linear programming models for water pollution control, Management Sci., B-166 to B-181.

Miller, W. L. and Gill, J. H., 1976, Equity considerations on controlling nonpoint pollution from agricultural sources, Water Resour. Bull. 12(2), 25j-261.

Monarchi, D. E., Kisiel, C. C., and Duckstein, L., 1973, Interactive multiobjective programming in water resources: A case study, Water Resour. Res. 9(4), 837-850.

Orlovsky, S. A., 1984, Multiobjective programming problems with fuzzy parameters, Control Cybernet. 13(3), 175-183.

Revelle, C. S., Loucks, D. P., and Lynn, W. R., 1968, Linear programming applied to water quality management, Water Resour. Res. 4(1), 1-9.

Sakawa, M., 1983, Interactive computer programs for fuzzy linear programming with multiple objectives, Internat. J. Man-Machine Studies 18, 489-503.

Sakawa, M. and Yano, H., 1985, Interactive fuzzy decision-making for multi-objective non-linear programming using reference membership intervals, Internat. J. Man-Machine Studies 23, 407-421.

Sakawa, M., Yano, H., and Yumine, T., 1987, An interactive fuzzy satisficing method for multiobjective linear-programming problems and its applications, IEEE Trans. Systems, Man, Cybernet. 17(4), 654661.

Streeter, H. W. and Phelps, E. B., 1925, A study of the pollution and natural purification of the Ohio River, Public Health Bull. 146, U.S. Public Health Service, Washington, D.C.

Zadeh, L. A., 1965, Fuzzy sets, Inform. and Control 8, 375-382.

Zimmerman, H. J., 1976, Description and optimization of fuzzy systems, Internat. J. Gen. Systems 2, 209-215.

Zimmerman, H. J., 1984, Fuzzy programming and linear programming with several objective functions, in Zimmerman, Zadeh, and Gaines (eds), Fuzzy Sets and Decision Analysis, Elsevier North-Holland, Amsterdam, pp. 109-121. 
Bogardi, I., Bardossy, A., and Duckstein, L., 1983. Regional management of an aquifer for mining under fuzzy environmental objectives, Water Resour. Res. 19(6), 1394-1402.

Brill, E., Liebman, J., and Revelle, C., 1976, Equity measures for exploring water quality management alternatives, Water Resour. Res. 12.

Chadderton, R. A., Miller, A.D., and McDonnell, A. J., 1981, Analysis of waste load allocation procedure, Water Resour. Bull. 17(5), 760-766.

Cohon, J. L., 1978, Multiobjective Programming and Planning, Academic Press, New York.

Ecker, J. G., 1975, A geometric programming model for optimal allocation of stream dissolved oxygen, Management Sci. 21(6), 658-668.

Gross, W. M., 1965, A lawyer looks at stream pollution, Civil Eng. 44-45.

Hathhorn, W. E., 1986, Optimal waste load allocation in a stream environment under uncertainty, MS Thesis, Department of Civil Engineering, University of Wyoming, Laramie, Wyoming.

Ignizio, J. P., 1982, Linear Programming in Single- and Multiple-objective Systems, Prentice-Hall, Englewood Cliffs, NJ.

Kickert, W. J., 1978, Fuzzy Theories on Decision-Making, Martinus Nijhoff, The Hague.

Korhonen, P., Wallenius, J., and Duckstein, L., 1987, Multiple objective linear programming over a fuzzy feasible set, in G. Evans, W. Karwowski, and M. Wilhelm (eds), Fuzzy Methodologies for Industrial and Systems Engineering, Elsevier, Amsterdam.

Liebman, J. C. and Lynn, W. R., 1966, The optimal allocation of stream dissolved oxygen, Water Resour. Res. 2, 581-591.

Loucks, D. P., ReVelle, C. S., and Lynn, W. R., 1967, Linear programming models for water pollution control, Management Sci., B-166 to B-181.

Miller, W. L. and Gill, J. H., 1976, Equity considerations on controlling nonpoint pollution from agricultural sources, Water Resour. Bull. 12(2), 25j-261.

Monarchi, D. E., Kisiel, C. C., and Duckstein, L., 1973, Interactive multiobjective programming in water resources: A case study, Water Resour. Res. 9(4), 837-850.

Orlovsky, S. A., 1984, Multiobjective programming probiems with fuzzy parameters, Control Cybernet. 13(3), 175-183.

Revelle, C. S., Loucks, D. P., and Lynn, W. R., 1968, Linear programming applied to water quality management, Water Resour. Res. 4(1), 1-9.

Sakawa, M., 1983, Interactive computer programs for fuzzy linear programming with multiple objectives, Internat. J. Man-Machine Studies 18, 489-503.

Sakawa, M. and Yano, H., 1985, Interactive fuzzy decision-making for multi-objective non-linear programming using reference membership intervals, Internat. J. Man-Machine Studies 23, 407-421.

Sakawa, M., Yano, H., and Yumine, T., 1987, An interactive fuzzy satisficing method for multiobjective linear-programming problems and its applications, IEEE Trans. Systems, Man, Cybernet. 17(4), 654661.

Streeter, H. W. and Phelps, E. B., 1925, A study of the pollution and natural purification of the Ohio River, Public Health Bull. 146, U.S. Public Health Service, Washington, D.C.

Zadeh, L. A., 1965, Fuzzy sets, Inform. and Control 8, 375-382.

Zimmerman, H. J., 1976, Description and optimization of fuzzy systems, Internat. J. Gen. Systems 2, 209-215.

Zimmerman, H. J., 1984, Fuzzy programming and linear programming with several objective functions, in Zimmerman, Zadeh, and Gaines (eds), Fuzzy Sets and Decision Analysis, Elsevier North-Holland, Amsterdam, pp. 109-121. 